\title{
Penetrating Heart Injuries Due to Puncture by Fractured Sternum or Ribs Following Blunt Trauma
}

\author{
Mahmut Tokur ${ }^{\mathrm{a}}$, Mehmet Ergin ${ }^{\mathrm{b}, \mathrm{e}}$, Mehmet Okumus ${ }^{\mathrm{c}}$, Can Kurkcuoglu ${ }^{\mathrm{d}}$
}

\begin{abstract}
Penetrating heart injuries typically present as ruptured myocardium resulting from sharp edged or pointed weapons and firearms. Blunt trauma to the thorax may also cause myocardial rupture by squeezing the heart between the bony structures of the thorax. However, the penetrating trauma resulting from the free ends of the fractured sternum or the ribs puncturing the heart and rupturing the myocardium is seldom seen. In this study, we present two cases of penetrating heart trauma resulting from fractured sternum and ribs puncturing the myocardium following a blunt chest trauma.
\end{abstract}

Keywords: Blunt trauma; Emergency surgery; Heart injury

\section{Introduction}

While $10.4 \%$ of the trauma cases requiring urgent management are related to the thorax region, only $0.3 \%$ to $1 \%$ of those cases involve myocardial damage $[1,2]$.

Manuscript accepted for publication September 5, 2011

${ }^{a}$ Kahramanmaras Sutcu Imam University, Medicine Faculty, Department of Thoracic Surgery, Kahramanmaras, Turkey

${ }^{\mathrm{b}}$ Selcuk University, Medicine Faculty, Department of Emergency Medicine, Konya, Turkey

${ }^{c}$ Kahramanmaras Sutcu Imam University, Medicine Faculty, Department of Emergency Medicine, Kahramanmaras, Turkey

dHarran University, Medicine Faculty, Department of Thoracic Surgery, Sanliurfa, Turkey

${ }^{\mathrm{e}}$ Corresponding author: Mehmet Ergin, Selçuk Universitesi Meram Tip Fakultesi Acil Tip AD, Akyokus, 42080 Meram, Konya, Turkey.

Email: drmehmetergin@gmail.com

doi:10.4021/jes104e

\section{Case Report}

\section{Case 1}

Following a fall from a height, a 40 years old male patient suffering from multiple trauma was brought into the emergency department (ED) presenting late stage shock. His computer tomography (CT) views revealed diffused brain edema and bilateral hemopneumothoraces, diffuse subcutaneous emphysema, bilateral multiple rib fractures, sternal fracture, pneumopericardium (Fig. 1A). The patient was intubated in the ED and bilateral tube thoracostomies were performed. He underwent right side-anterolateral thoracotomy. The pericardium was discovered to be ruptured on the right side and a pericardial tamponade had developed. Following the removal of blood in the pericardial sac, a 1 $\mathrm{cm}$ myocardial laceration on the front side of the right ventricle was noted (Fig. 1B). The laceration was located immediately posterior to the sternal fracture. The laceration was thought to result from the puncture by the sharp ends of a fractured sternum and/or ribs. The laceration was repaired with $2 / 0$ propylene suture and pericardial patch. However, he died on the 20th day post operation, due to the multiple organ failure resulting from pneumonia and sepsis which developed following the adult respiratory distress syndrome (ARDS).

\section{Case 2}

A 53 years old male occupant of a motor vehicle involved in a motor vehicle accident and was brought into the ED. The patient was in the state of hypovolemic shock. His physical exam revealed bilateral multiple rib fractures and depressed deformity and flail chest on the front side parasternal region of the left hemithorax. The thorax CT revealed bilateral hemopneumothoraces, diffuse bilateral pulmonary contusions, multiple rib fractures, diffuse subcutaneous emphysema, free rib ends detached from the sternum on the left parasternal region and pneumopericardium (Fig. 2A). Bilateral tube thoracostomies were performed. A left side-anterolateral thoracotomy was performed initially and a $0.5 \mathrm{~cm}$ laceration 


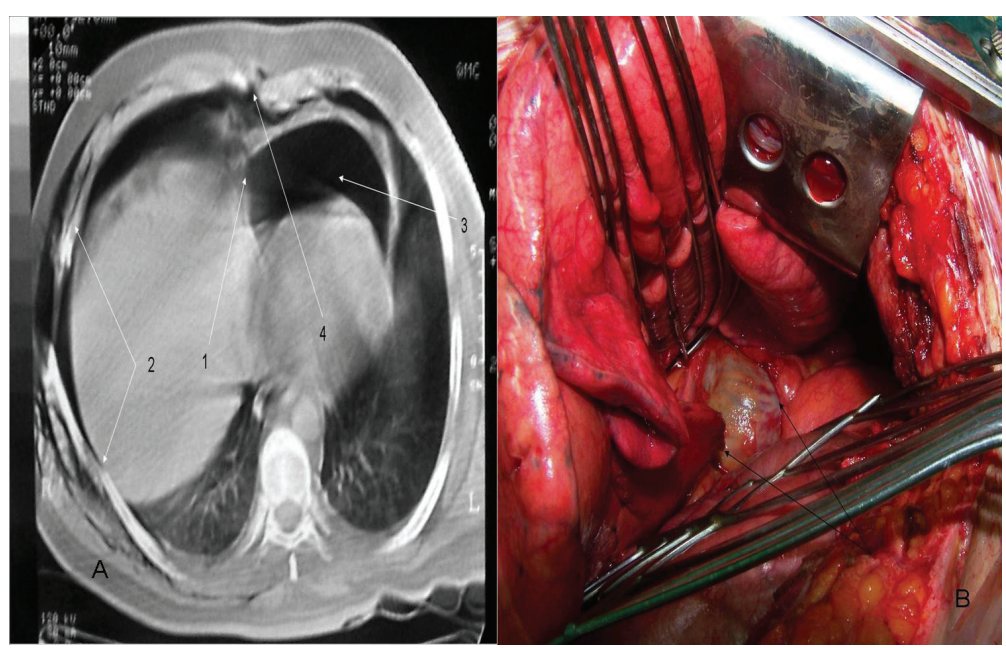

Figure 1. A is demonstrating pericardial rupture (1), rib fractures (2), pneumopericardium (3) and sternal fracture (4). B is demonstrating pericardial rupture on the right.

was noted on the left ventricle. The incision was extended as clamshell incision as bilateral hemorhagic spots and heart injury was noted (Fig. 2B). The laceration on the ventricle was thought to result from a puncture caused by the fractured ends of the left parasternal ribs and it was repaired with $2 / 0$ propylene suture using a "U" technique. The patient was mechanically ventilated for 14 days post surgery and he was discharged on the 32 nd day.

\section{Discussion}

Injuries to the heart after blunt trauma can result from several mechanisms. The most common mechanism is though to be squeezing of the heart between the sternum and the vertebrae and the transfer of increased intrathoracic pressure to the atria and the ventricles via vena cava and pulmonary veins [1-3].
While chances of seeing cardiac rupture from blunt thorax traumas in live patients are low $(0.3 \%)$, the mortality rate is quite high (80\%) [4]. Among the types of lesions seen in the heart injuries resulting from blunt trauma are myocardial contusions, lacerations, ruptures, valve deficiencies, thrombus, septal defects, heart herniation and pericardial rupture. Penetrating injuries can result from the punctures caused by the bony structures in the chest wall [1-3]. In the literature there is no mention on the frequency of heart injuries resulting from punctures caused by fractured bone ends. In our ED, 11 penetrating heart injuries have been treated and only two $(18 \%)$ of them resulted from punctures caused by the fractured bone ends.

On the other hand, authopsies performed after deaths related to blunt thorax trauma reveal that the myocardial ruptures are the most common cause of mortality in these types of injuries. It is also shown that ventricular ruptures are seen more commonly compared to the ruptures of the atria. Rup-

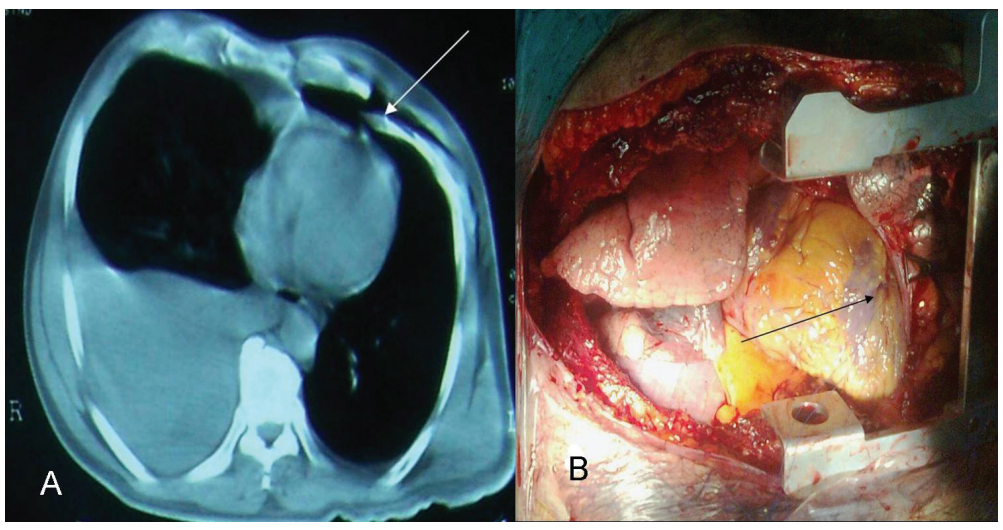

Figure 2. A is demonstrating hemothorax on the right and free ends of parasternal fractured ribs on the front left. $B$ is demonstrating clamshell incision and repaired laceration on the front side of the left ventricle. 
tures are seen most frequently on the right ventricle followed by the left ventricle, right atrium and the left atrium $[1,2]$.

Penetrating cardiac injuries secondary to blunt trauma and multiple trauma patients are often missed. Penetrating heart injuries should be considered in cases where there is hemopneumopericardium noted in the thorax CT, injuries present in the front side of the chest wall, especially parasternal rib detachments, flail chest, sternal fracture, massive hemothorax and in patients who are unresponsive to the fluid-blood replacement therapy [5-7].

Isolated sternal fractures seldom cause heart injuries, whereas sternal fractures in combination with multiple rib fractures and/or flail chest can cause perforations to the heart $[8,9]$. Penetrating heart injuries resulting from blunt chest traumas must be treated in the same manner as the other penetrating heart injuries. Anterolateral and posterolateral thoracotomies, sternotomies and clamsheel incisions in cases where bilateral pulmonary injuries and heart injuries are seen could be performed [8-10].

\section{Conclusion}

Penetrating heart injuries resulting from punctures caused by the bony ends of a fractured sternum and/or ribs in blunt chest traumas have higher mortality rates compared to the injuries caused by the firearms oredged and sharp pointed objects. Even if the lacerations to the heart can be repaired by rapid surgical interventions, those patients may still die at a later stage as a result of certain respiratory system pathologies that develop following diffuse pulmonary lacerations, multiple rib fractures and ruptured diaphragm. Also, secondary pulmonary infections, mediastinitis, sepsis and ARDS can be seen in patients receiving long term ventilatory support.

\section{References}

1. Parmley LF, Manion WC, Mattingly TW. Nonpenetrating traumatic injury of the heart. Circulation. 1958;18(3):371-396.

2. Brathwaite CE, Rodriguez A, Turney SZ, Dunham CM, Cowley R. Blunt traumatic cardiac rupture. A 5-year experience. Ann Surg. 1990;212(6):701-704.

3. Huguet M, Tobon-Gomez C, Bijnens BH, Frangi AF, Petit M. Cardiac injuries in blunt chest trauma. J Cardiovasc Magn Reson. 2009;11:35.

4. Shorr RM, Crittenden M, Indeck M, Hartunian SL, Rodriguez A. Blunt thoracic trauma. Analysis of 515 patients. Ann Surg. 1987;206(2):200-205.

5. Kaul P, Somsekhar G, Macauley G. Secondary left ventricular injury with haemopericardium caused by a rib fracture after blunt chest trauma. J Cardiothorac Surg. 2006;1:8.

6. Roth T, Kipfer B, Takala J, Schmid RA. Delayed heart perforation after blunt trauma. Eur J Cardiothorac Surg. 2002;21(1):121-123.

7. Juan CW, Wu FF, Lee TC, Chen FC, Hu YR, Yu YT. Traumatic cardiac injury following sternal fracture: a case report and literature review. Kaohsiung J Med Sci. 2002;18(7):363-367.

8. Galvin IF, Costa R, Murton M. Fractured rib with penetrating cardiopulmonary injury. Ann Thorac Surg. 1993;56(3):558-559.

9. Sadaba JR, Oswal D, Munsch CM. Management of isolated sternal fractures: determining the risk of blunt cardiac injury. Ann R Coll Surg Engl. 2000;82(3):162-166.

10. Gao JM, Gao YH, Wei GB, Liu GL, Tian XY, Hu P, Li $\mathrm{CH}$. Penetrating cardiac wounds: principles for surgical management. World J Surg. 2004;28(10):1025-1029. 